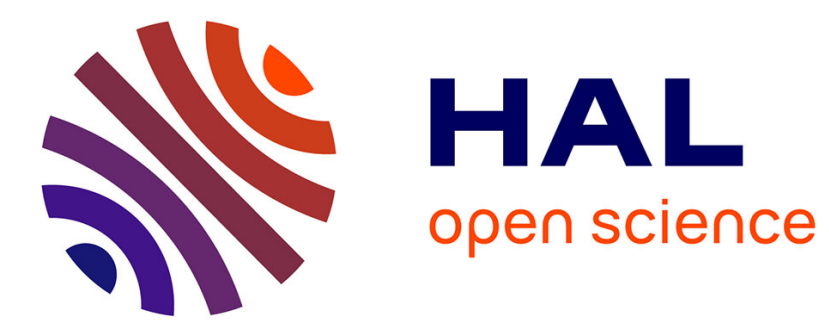

\title{
A Feedback on an Industrial Application of the FORMAT Methodology
}

Sebastien Dubois, Roland De Guio, Aurélien Brouillon, Laetitia Angelo

\section{To cite this version:}

Sebastien Dubois, Roland De Guio, Aurélien Brouillon, Laetitia Angelo. A Feedback on an Industrial Application of the FORMAT Methodology. 18th TRIZ Future Conference (TFC), Oct 2018, Strasbourg, France. pp.290-301, 10.1007/978-3-030-02456-7_24 . hal-02279777

\section{HAL Id: hal-02279777 https://hal.inria.fr/hal-02279777}

Submitted on 5 Sep 2019

HAL is a multi-disciplinary open access archive for the deposit and dissemination of scientific research documents, whether they are published or not. The documents may come from teaching and research institutions in France or abroad, or from public or private research centers.
L'archive ouverte pluridisciplinaire HAL, est destinée au dépôt et à la diffusion de documents scientifiques de niveau recherche, publiés ou non, émanant des établissements d'enseignement et de recherche français ou étrangers, des laboratoires publics ou privés. 


\title{
A feedback on an industrial application of the FORMAT methodology
}

\author{
Sebastien Dubois ${ }^{1}$, Roland De Guio ${ }^{1}$, Aurélien Brouillon ${ }^{1}$ and Laetitia Angelo ${ }^{1}$ \\ ${ }^{1}$ CSIP, ICube Laboratory, INSA de Strasbourg, 24 bld de la Victoire, Strasbourg, France \\ sebastien.dubois@insa-strasbourg.fr
}

\begin{abstract}
One of the main issues of industrial product evolution planning is the current state of the art, related to the product itself, its market competitors, and also the available resources that can become parts of the future product. Moreover, to plan evolution, it is required to well understand how the performance of the product will be evaluated, on a future market, and surely it won't be the same performance criteria as today habits.

This issue has been tackled and defined as Analysis of Initial Situation. A combination of TRIZ based approaches and Design of Experiments has been defined to clarify the problem to be solved. But all these approaches are dedicated to analyze today product and to choose the prior problem to be considered, but these methods have not been defined to analyze long-term evolution planning of products.

For this long-term planning, a method, FORMAT, has been developed and proposed. The purpose of this article is to describe the application of this methodology on an industrial case, to plan the evolution of kitchen hoods. The article will state the different methods to perform the Analysis of Initial Situation but also the benefits and the difficulties of FORMAT application.
\end{abstract}

Keywords: Analysis of Initial Situation, FORMAT method, long-term prospective.

\section{Introduction}

Solving problems has always been one of the main concerns for industrial engineers. And lot of methods to help them in this task have been developed, with different aims and ends $[1,2]$. One can recognize various methods to:

- help in describing the design process at an operational level [3] or at a cognitive level [4],

- help in defining the problems to be tackled during design process in regard of the generated value [5],

- help in generating design concepts either algorithmically [6], either with humans [7],

- help in evaluating design concepts [8]. 
Among these different proposals, TRIZ has been widely recognized as increasing the inventive level of proposed concepts and as enabling engineers to propose new solutions' concepts. From the end of 50's till the end of 80's, TRIZ has been developed to help engineers to be more creative. This development has lead to the proposal of a general approach based on 5 steps:

1. The analysis of initial situation, which objective is to elicit the specific conditions under which problem appears, the inherent contradictions and also to choose the root cause of problem, the prior contradiction to be solved.spithe definition of the problem. The objective of this step is to clarify the limits of the problem, i.e. the borders in which the solution can be found and thus to specify if the problem is a maxi or a mini problem.

2. The definition of the ideal solution aims to separate lower-level solution from higher-level ones by intensifying the constraints for solution concept synthesis.

3. The definition of the physical solution enables to select relevant information for concept solution synthesis, i.e. to identify inventive mechanisms enabling to satisfy the conditions of the ideal solution.

4. The definition of the technical solution reinforces the concept of the physical solution by defining which resources can be used and how these resources are used to fit the physical solution.

In border of this 4-steps general approach, several versions of ARIZ [9] have been defined, but the last one defined by Altshuller [10] does not fit with the first step. The analysis of initial situation has not been developed anymore and is still one key stake in problem solving process. The matter was the recognition that the proposed method for this step was not as developed as the methods inherent to the other steps [11].

In [12], the authors proposed to perform the Analysis of Initial Situation with sequential experimentation. This enabled to create a continuum between methods dedicated for optimization and the ones developed for invention. This continuum is still under development today $[13,14]$.

In parallel the consideration of Technical Systems' Laws of Evolution has also been considered as a way to state the level of maturity of a considered problem and thus enable the elicitation of the key problems to solve [15]. An European Project has been developed in this direction and lead to the proposal of the FORMAT method [16]. Thus an "innovative forecasting methodology" has been proposed "to support strategic decisions in industrial R\&D activities, by managing the multi-disciplinary complexity of current systems and by anticipating the future characteristics of products and processes".

In this paper, the authors will first introduce three known ways to perform the Analysis of Initial Situation: ARIZ-85A, the use of Design of Experiments, and the FORMAT method, then the general required steps will be elicited. The application of the FORMAT method will then be illustrated. And at last some discussion and conclusion will be proposed.

1 http://www.format-project.eu/about 


\section{Analysis of Initial Situation}

In this part, three ways to perform the Analysis of Initial Situation will be presented: the one developed by G. Altshuller, ARIZ-85A, the proposal of the authors about the way to build a continuum between optimization methods and inventive ones, and, finally, the FORMAT project.

\subsection{ARIZ-85A}

Throughout the development of a method to tackle inventive problems, several versions of ARIZ (the Algorithm for Inventive Problem Solving) have been proposed as the results of seminars in which several problems have been tackled by groups of people, to identify the strong and weak points of the proposed method. By the end of the 50's the patterns of technological evolution have been included in the method. During the 60's the versions of ARIZ pointed out the importance of the problem statement, as ARIZ-64 introduced the section "Clarifying and verifying the problem statement", which has been decomposed in two different parts in 1968. In the 80's, starting with ARIZ-82, the method has been targeted specifically to solve difficult non-typical problems. And in 1985, "the former first chapter is no longer part of the algorithm as it is not rigorous enough compared to the other chapters" [17]. Thus the last version of this first chapter, that can be used to perform the Analysis of Initial Situation is ARIZ-85A [18].

ARIZ-85A is a set of 9 steps:

1. Definition of the final goal, which aims at defining the global objective of the problem, from technical and economical point of view

2. Investigate the bypass approach, to state how the problem occurs at different levels of the system

3. Choice of the considered problem, at which level it will be tackled

4. Determination of the required characteristics, to state the list of Evaluation Parameters

5. Intensification of the required characteristics, the intensification being one the TRIZ mean to propose more robust concept solution.

6. Definition of the constraints

7. Application of the inventive standards, to state if the problem is inventive or not

8. Analysis of the patents, also a mean to clarify if an existing solution, even coming from another domain can be applied. But this step raises the question of the non application of the laws of technical systems evolution.

9. Application of the STC operator, another mean to apply intensification.

In these 9 steps, one can formulate 4 main questions to be tackled: What is the scope of the problem? What is the system to consider? What is the strategic context? What is the problem? These 4 main questions, which will be used to represent the complementary aspects of the different methods, and the related questions of ARIZ-85A are represented on figure 1 . 


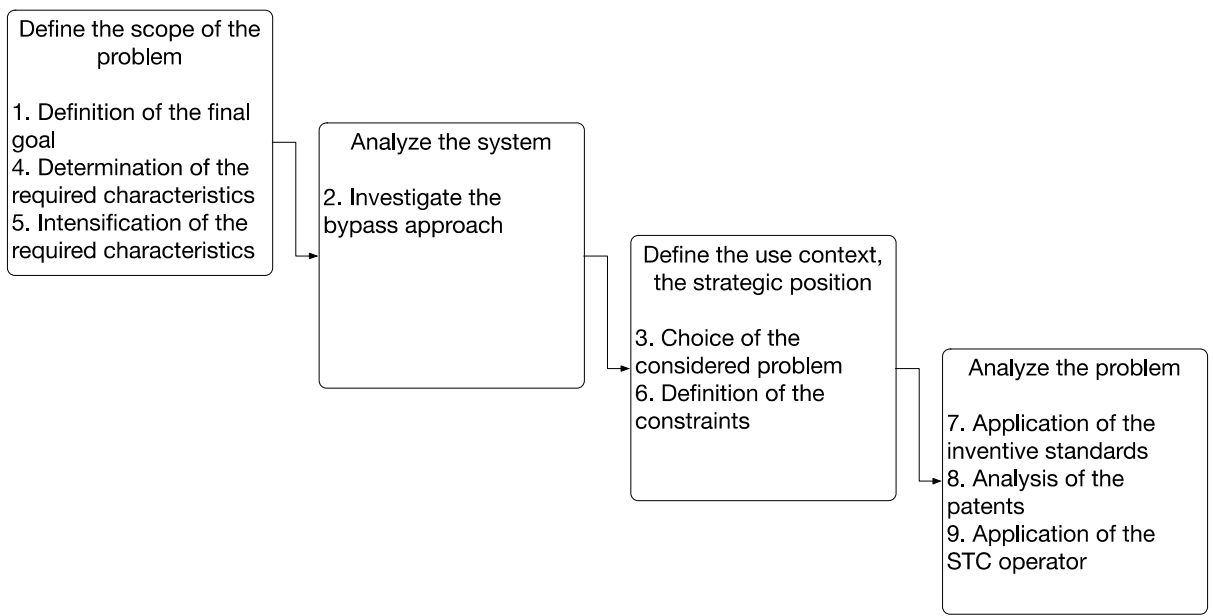

Fig. 1. ARIZ-85A process

\subsection{Design of experiments based methods}

In [12] the authors proposed a 6 steps approach to merge optimization and invention methods. The use of sequential experimentation, a well-known sequence of different mathematical tools, aimed at fulfilling Analysis of Initial Situation and to identify the contradiction to consider for problem resolution. The 6 steps are:

1. Principal component and factor analysis to identify how many action parameters (AP) influence the evaluation parameters (EP)

2. Fractional design of experiments to identify which AP influence each EP

3. Factorial design of experiments with center-points to identify the direction which will allow to move towards an optimum

4. Response surface method to locate the optimum solution

5. Generalized System of Contradictions if the optimum does not satisfy the objective

6. OTSM-TRIZ techniques to solve the contradiction

These steps mainly participate to the questions of the system to be considered and to the analysis of the problem, as illustrated on figure 2 . 


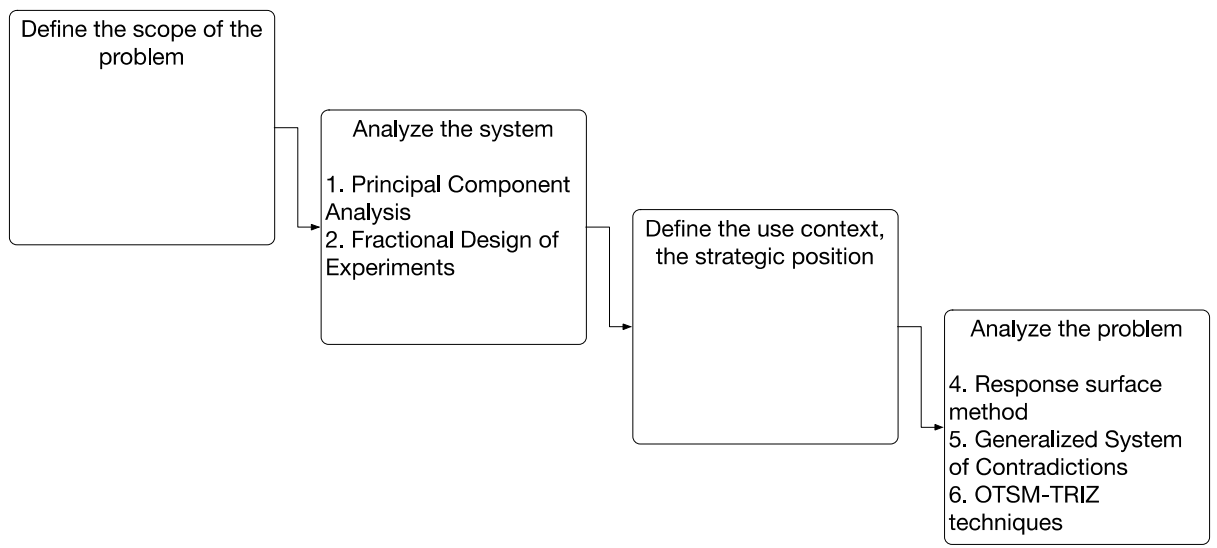

Fig. 2. Design of Experiments based method contributions on the 4 questions

It is thus already obvious that the methods based on optimization approaches could bring benefits to the Analysis of Initial Situation, and that they way the Design of Experiments should be defined would also benefits from TRIZ-based methods. But one aspect that is still missing with these two methods is the consideration of the maturity level of the considered system and more generally the evolution of this system.

\subsection{Format}

FORMAT method focuses on making long-term prospective, and thus is mainly built on the crossed use of logistic and substitution curves [15] and qualitative elements to interpret them. These project FORMAT aimed at answering "the need to introduce structured methods and tools capable to support strategic decisions in industrial R\&D activities, by managing the multi-disciplinary complexity of current systems and by anticipating the future characteristics of products and processes." ${ }^{2}$

Table 1. Format stages [16]

\begin{tabular}{|l|l|l|}
\hline \multicolumn{1}{|c|}{ Stage } & \multicolumn{1}{|c|}{ Main Functions } & \multicolumn{1}{|c|}{ Questions and duties } \\
\hline $\begin{array}{l}\text { FOR: Diagnose ques- } \\
\text { tions and plan project }\end{array}$ & $\begin{array}{l}\text { Prepare and make decisions } \\
\text { about forecasting project } \\
\text { Define boundaries/resources of } \\
\text { forecasting project }\end{array}$ & $\begin{array}{l}\text { WHY do we need to know } \\
\text { the future? } \\
\text { WHAT do we need to know } \\
\text { about the future? } \\
\text { HOW do we plan to learn } \\
\text { about future? }\end{array}$ \\
\hline $\begin{array}{l}\text { M: Define the system } \\
\text { for forecast and study } \\
\text { contexts }\end{array}$ & $\begin{array}{l}\text { Review existing knowledge } \\
\text { about system }\end{array}$ & $\begin{array}{l}\text { WHAT the System To Fore- } \\
\text { cast (STF) is for? (WHY we } \\
\text { need the STF?) } \\
\text { WHICH systems allow to get } \\
\text { the same results? } \\
\text { HOW to measure the perfor- }\end{array}$ \\
\hline
\end{tabular}

2 http://www.format-project.eu/about 


\begin{tabular}{|l|l|l|}
\hline & & $\begin{array}{l}\text { mances and the expenses of } \\
\text { the STF and its alternatives? } \\
\text { WHAT the STF and its main } \\
\text { alternative(s) are, were and } \\
\text { are expected to be? }\end{array}$ \\
\hline $\begin{array}{l}\text { A: Develop forecast for } \\
\text { defined system and } \\
\text { context }\end{array}$ & $\begin{array}{l}\text { Identify a system of problems } \\
\text { that drives evolution of system } \\
\text { Recognize evolutionary trends } \\
\text { for identified system } \\
\text { Identify changes of perfor- } \\
\text { mance characteristic in time } \\
\text { Aggregate and validate results } \\
\text { of qualitative and quantitative } \\
\text { studies into forecast }\end{array}$ & $\begin{array}{l}\text { Extract limiting resources } \\
\text { from problems of STF } \\
\text { Define set of solutions ad- } \\
\text { dressing limiting resources } \\
\text { Fit data-series about parame- } \\
\text { ters measuring performance } \\
\text { \& expenses } \\
\text { Build conclusions about } \\
\text { future traits for STF }\end{array}$ \\
\hline $\begin{array}{l}\text { T: Prepare report and } \\
\text { present results }\end{array}$ & $\begin{array}{l}\text { Transfer results of study to } \\
\text { decision makers }\end{array}$ & $\begin{array}{l}\text { Transfer the forecasting } \\
\text { results to beneficiaries / } \\
\text { decision makers }\end{array}$ \\
\hline
\end{tabular}

All these steps also aim at identifying the general trends of evolution of technical systems, and thus, at formulating which problems are to be considered for resolution. Then, the method also enables to perform an Analysis of Initial Situation, and the benefits of each stage in regard of the 4 generic questions is presented in figure 3 .

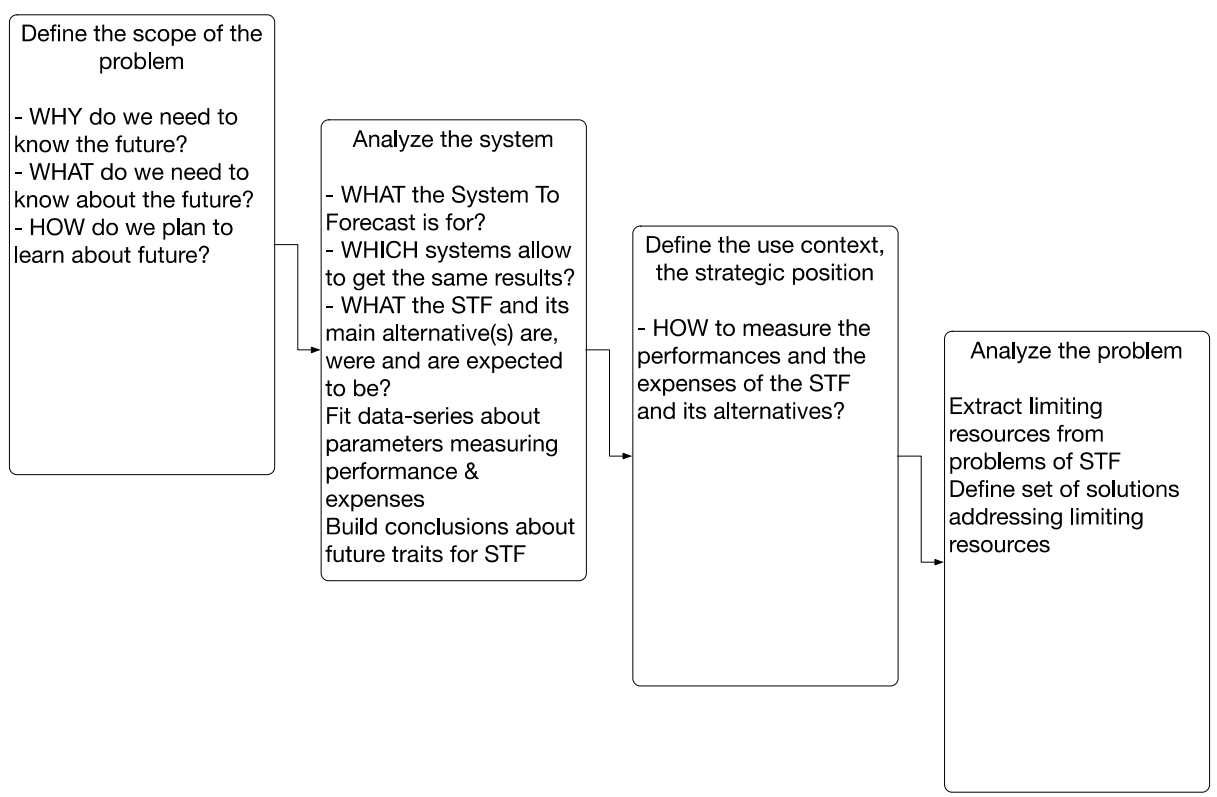

Fig. 3. Questions and duties of FORMAT methods' contributions on the 4 questions

\subsection{Comparison of the presented methods}

The three presented methods, ARIZ-85A, Design of Experiments based method to hierarchize contradictions, and FORMAT, could be recognized at three ways to per- 
form the Analysis of Initial Situation. Each being more complete, or at least different, in the way to answer to each of the 4 mains questions. It seems thus quite obvious that complementary aspects could be built based on these differences.

In this article, the authors will present their application of the FORMAT method, on a case study, and will show the benefits they recognize in this application, but also, the difficulty they met.

\section{Case study}

\subsection{Presentation of the case}

The presented article is the application of the FORMAT method on an industrial case to investigate the long-term evolution of the kitchen hoods. The objective was to make a state-of-art of the current technologies, their advantages, their limitations, and to understand which of these technologies will be the leading technology in the future. To tackle this question, a group composed of 3 experts from enterprise and 2 TRIZ experts from laboratory was formed. The company aimed at creating differentiation on the market by proposing high quality products. The initial purpose was to apply FORMAT method as is, but, quickly, it has been quite obvious that complementary tools were necessary to answer the questions, due to lack of formalization in the FORMAT method, and also because we could not obtain required data to perform relevant analysis of logistic curves.

The available information the group had at the beginning of the project was:

- Historical data of the enterprise products from 1966 to 2015

- Functional analysis of kitchen hood

- Safety and operating standards

- Partial studies of filtration technologies and of the elements to be filtered

Thus, there were some missing information that have been capitalized throughout the project:

- The clarification of the enterprise strategy

- The market tendencies and the customers' needs

- The differentiation criterions for the customer

- The alternative technologies, not reduced to those available on the market

- Current and objective performances

- Technical constraints

- Pareto front and trade-off of current existing systems

Based on this missing information and trying to fulfill the first steps of FORMAT method, some ascertainments were made and some limitations of the direct applicability of the method were pointed out. 


\subsection{Ascertainments about FORMAT method}

Performing the FOR step of the method tackled some strategic questions, which enabled to clarify the previously cited missing information and to well clarify what the project aimed at. It also clarified the necessity to better investigate current systems, the market and technological competitors and a clear formulation of what performance means for the system. In fact, some elements of the $M$ step were required to well answer FOR step.

The starting point of the method of the M step is to define the Main Useful Function of the observed system, thus the limits of this system and also its operating principle. One first conclusion about the analysis of the system was that the experts of the company were mainly oriented by the Evaluation Parameters defined in border of the standards. And one of the conclusion of the group was that the standards are proposed to evaluate existing systems, in regard of safety purposes, but not appropriate to evaluate future, not yet existing systems, in regard of performances.

In the method it is proposed to complete a multi-screen analysis of the system and to use the Element-Name-Value (ENV) model to formulate the criteria to measure the performances and expenses [20]. Only analyzing system through the TRIZ based models gives a partial understanding of this system, mainly functional. It was thus decided to complete this TRIZ system description with an analysis of the system also based on activities, using an IDEF0 ${ }^{3}$ and $\mathrm{SADT}^{4}$ analysis, as proposed in the method.

It was also decided to have a global understanding of who is the customer, and this customer has been analyzed throughout a systemic perspective, then 4 kinds of potential future users were interviewed to point out their main concerns:

- The demanding customers for their high demand on functionalities

- The private users, as they will be the end-users of the product

- The kitchen furniture dealers to understand the constraints linked with the assembly constraints, transportability, and so on of the future system

- The professionals, renowned chefs for their high understanding of the current systems' limits and main functional advantages of future systems

Moreover, to better state the current limits of known working principles, the analysis of the market has been completed by kitchen hoods modeling and simulation.

At last, the use of logistic curves in order to plan substitution of technologies has led the group to the difficulty in having robust long-term data of past systems enabling to fit with accuracy the curves. It has then been difficult to have reliable conclusions on the analysis of logistic curves.

\subsection{Realized process and main results}

The figure 4 details the process as it has finally been conducted, which starts at the top left of the figure. After a first realization of the stage "FOR" we could have access

3 http://www.idef.com

4 http://www.lsis.org/dea/M6optionD/Exp-GL41-SADT.pdf 
to a further marketing study and were able to question the participants of the whole value chain of the kitchen hoods. The first pass provided a first family of assessment criteria that were adjusted in the second study. Let us notice that it is not a linear process; lot of backtrackings were necessary to validate answers to initial questions, and the benefits of adding model and simulation to poor descriptions provided by the state of the art have been well appreciated to demonstrate the potential and limits of current working principles.

The available data about the sales on the market enabled to propose logistic curves, but not on technological information, only on the kind of settlement of the system. The analysis was performed with data from the world sale volume from 2004 to 2014. The collected data were then transposed, with dedicated tools (Logistic Substitution Model $I I^{5}$ and $\operatorname{Loglet} \operatorname{Lab}^{6}$ ), into logistic curves, which are a graphical representation of the innovations' diffusion in the technologies' life cycle [21]. However, this analysis, presented on figure 5, remains superficial, as the amount of analyzed data is not sufficient enough to guarantee the robustness of the results. Nevertheless the global qualitative substitution that can be seen on figure 5 confirms the feeling of the marketing about the market. But as we explained at the beginning of this paragraph, these data represents settlement of the system substitution and not technology substitution.

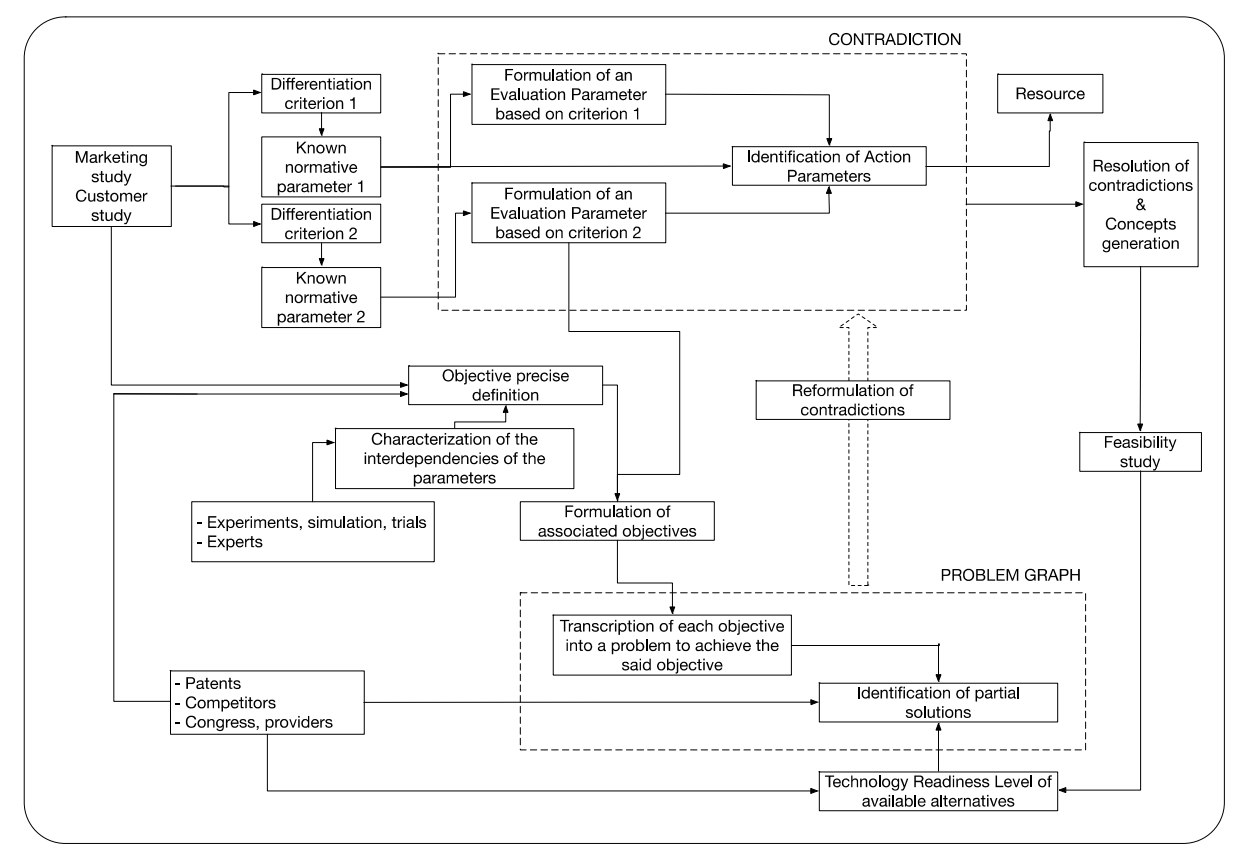

Fig. 4. Detailed process of Analysis of Initial Situation in the case study

$5 \mathrm{http}: / /$ www.iiasa.ac.at

6 https://logletlab.com 


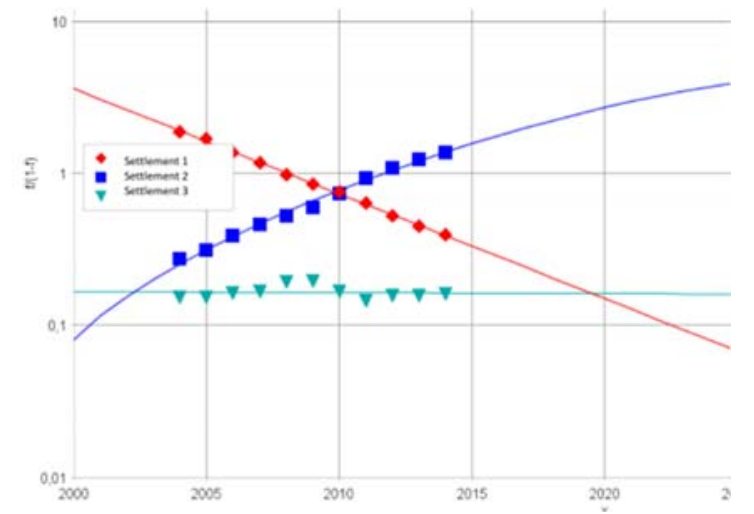

Fig. 5. Substitution curves for 3 different settlements of system

Another interesting result, based on the systemic description of the customers is the elicitation of more relevant set of Evaluation Parameters (EP). The customers study and other participants to the value chain pointed out five families of parameters but the standards only provided three measurable EP shared among two of them. The final set was composed of seventeen EP, as illustrated on figure 6. Some parameters like acoustical comfort have been added due to the evolution noise analysis in other domains. Others like uptake measurable parameters have been defined by the working group. The new set of assessment parameters allowed a better understanding of the state of the art and TRL of potential solutions related to PE families. We did not seek, through lack of resources, to carry out a quantitative analysis of the evolution, i.e. logistic curves of the new EPs. Nevertheless we did evaluate the actual performance of each component either with data from literature or from simulations and experiments. We have also established, through this technical and scientific state of the art, to what extent some performance tradeoffs observed on current systems can be potentially removed. It was proposed to address the remaining performance dilemma with TRIZ. The motivation for using TRIZ was to complete the state of the art and see whether it was possible with available knowledge to overcome the remaining contradiction or at least get a better understanding of the problem.

The decision how to go further was done by the stake holders based on the produced knowledge. 


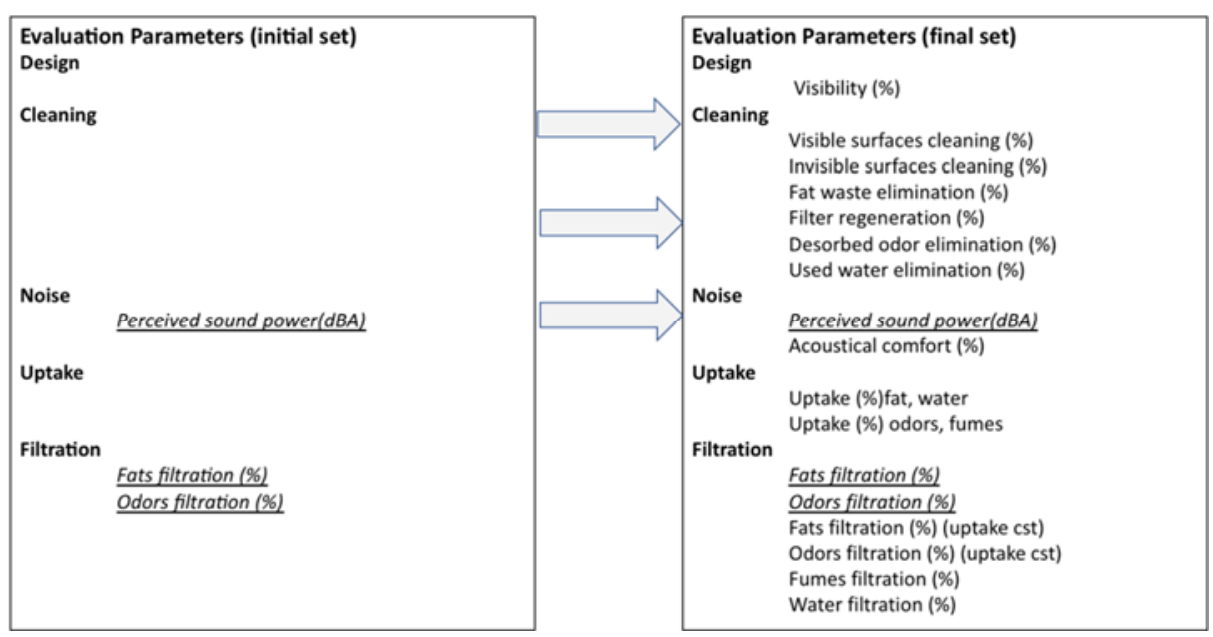

Fig. 6. Initial and final set of Evaluation Parameters

\section{$4 \quad$ Discussion and perspectives}

The study performed with this company aimed at identifying future technological trends but also at determining the innovation projects that will be launched in the next coming years. The results are very satisfying as several prior problems have been formulated and gave birth to development projects that are still in progress. Moreover it helped in building a better understanding of the considered system, its evolution and the main performance criterion that have to be considered. The proposed method also gave new development opportunities for the company, as, for example, the systematization of modelization and simulation in development projects. The system modeling and later validating allowed getting information about system that was not available before. This new knowledge may change the way to address the competition.

Concerning the FORMAT method, some of the conclusions that have been pointed out during the application are:

- All the proposed steps in FORMAT are necessary to be performed, but it cannot be complied as a linear process, and some answers of further steps are required to well assess the answers of first steps, especially between FOR and M steps. Perhaps should FOR, M, A, T sequence be considered as a functional model, and consistencies checking between the sequences be added.

- TRIZ based models have to be completed with other systems' description models to have a more global understanding of the system

- One of the main benefits, but also one of the main difficulties in FORMAT method is the use of logistic and substitution curves. It gives very interesting information about the remaining years to improve an existing system, and the necessity to develop new generation one. But the collect of reliable data is really hard, and these data are not necessarily available. There is still research work to do in order to pro- 
vide companies with this data. One way to address the question could be to provide companies with ways to collect relevant information progressively so that it is available when needed.

If a new project on long-term prospective of a system will have to be considered, the first concern will then be to consider which data are available and how reliable they are. Then the more performant system will be considered, modelled, and optimization of this system will be looked for by simulation. The use of Design of Experiments to guide the simulation will also enable to point out the limits of the considered working principle and to identify both innovation directions, and contradictions to be solved, as presented in $[13,14,22]$. Depending on the specific situation the latest approach have advantage but it might also have some limitations. Indeed the use of modeling and simulation can fasten the knowledge acquisition when a good model is available quickly and when the system is too complex for human to catch relations between the design parameters and evaluation parameters or when experiments on real system are impossible, too much time consuming or too expensive. But, when the model accuracy is not known, the process to build an accurate and credible model can limit the efficiency of the method. Independently from the resource consuming of this process the efficacy of the use of simulation might be improved by finding a way to evaluate beforehand the relevant degrees of accuracy and credibility that will allow the stake holders to use the results when deciding.

\section{References}

1. Carmichael DG: Problem Solving for Engineers. CRC Press. 432 (2013).

2. Horvath L and Rudas IJ: Modeling and Problem Solving Techniques for Engineers. Elsevier Academic Press (2004).

3. Pahl G and Beitz W: Engineering design: a systematic approach. New York: Springer Verlag (1988).

4. Le Masson P, Weil B and Hatchuel A: Design Theory: Methods and Organization for Innovation. Springer International Publishing (2017).

5. NORmalisation AFd: Analyse de la Valeur, Caractéristiques Fondamentales. 1990 (1990).

6. Haupt RL and Haupt SE: Practical Genetic Algorithms with CD-ROM. Wiley-Interscience (2004).

7. Altshuller GS: Creativity as an Exact Science. New York: Gordon and Breach (1988).

8. Suh NP: Axiomatic Design: Advances and Applications. New York: Oxford University Press (2001).

9. Altshuller GS: The Innovation Algorithm: TRIZ, systematic innovation and technical creativity. Technical Innovation Center, Inc. ed. Worcester, MA (1999).

10. Altshuller GS: Algorithm of Inventive Problem Solving (ARIZ-85C). 1985, OTSM-TRIZ Technologies Center: Minsk, Belarus. p. 32 (1985).

11. Zlotin B and Zusman A ARIZ on the Move. TRIZ Journal, 1999.

12. Burgard L, Dubois S, De Guio R, et al.: Sequential experimentation to perform the Analysis of Initial Situation, in TRIZ Future Conference 2011, G. Cascini and T. Vaneker, Editors. 2011, Institute of Technology Tallaght: Dublin, Ireland. p. 35-45 (2011).

13. Lin L, Rasovska I, De Guio R, et al.: "Optimization Methods for Inventive Design", in TRIZ - The Theory of Inventive Problem Solving, D. Cavallucci, Editor. Springer. p. 151185 (2017). 
14. Dubois S, Chibane H, De Guio R, et al.: From simulation to contradictions, different ways to formulate innovation directions, in ETRIA TRIZ Future Conference 2017. 2017: Lappeenranta, Finland (2017).

15. Kucharavy D, Schenk E and De Guio R: Long-Run Forecasting of Emerging Technologies with Logistic Models and Growth of Knowledge, in 19th CIRP Design Conference Competitive Design. 2009: Cranfield University. p. 277 (2009).

16. Consortium F: FORMAT - the handbook. 190 (2014).

17. Kucharavy D: Theory and practice of ARIZ, in Materials for Master of Innovative Design, Module 6, INSA de Strasbourg. 2005 (2005).

18. Altshuller GS, Zlotin B and Philatov VI: "Analysis of the Initial Situation", in Profession: to search for new. Kartya Moldovenyaske Publishing House: Kishinev. p. 181-182 (1985).

19. Dubois S, De Guio R, Rasovska I, et al.: From simulation to inventive problem resolution, a global method, in 21st International Conference on Engineering Design (ICED 17), S.Š. Anja Maier, Harrison Kim, Michael Kokkolaras, Josef Oehmen, Georges Fadel, Filippo Salustri, Mike Van der Loos, Editor. 2017: Vancouver, Canada. p. 503-512 (2017).

20. Nikulin Chandia CN: A Method for Forecasting Design Requirements Based on Experts' Knowledge and Logistic Growth Model, in Dipartimento di Meccanica. 2015, Politecnico di Milano (2015).

21. Kucharavy D and De Guio R: Logistic Substitution Model and Technological Forecasting, in TRIZ Future 2008 - Synthesis in Innovation. 2008: Enschede, Netherlands. p. 65-73 (2008).

22. Rasovska I, De Guio R and Dubois S: Using dominance relation to identify relevant generalized technical contradictions in innovative design, in IESM 2017. 2017: Sarrebruck, Germany (2017). 